\title{
Bone Marrow Transplantation Prolongs Life Span and Ameliorates Neurologic Manifestations in Sandhoff Disease Mice
}

\author{
Francine Norflus, ${ }^{\star}$ Cynthia J. Tifft, ${ }^{\star \ddagger}$ Michael P. McDonald, ${ }^{\S}$ Gregory Goldstein, ${ }^{\S}$ Jacqueline N. Crawley, ${ }^{\S}$ \\ Alexander Hoffmann, Konrad Sandhoff," Kinuko Suzuki," and Richard L. Proia* \\ * Genetics and Biochemistry Branch, National Institute of Diabetes and Digestive and Kidney Diseases, National Institutes of Health, \\ Bethesda, Maryland 20892; 'Department of Medical Genetics, Children’s National Medical Center, Washington, District of Columbia \\ 20010; ${ }^{8}$ Section on Behavioral Neuropharmacology, Experimental Therapeutics Branch, National Institute of Mental Health, National \\ Institutes of Health, Bethesda, Maryland 20892; "Kekulé-Institut für Oganische Chemie und Biochemie der Universität Bonn, 53121 Bonn, \\ Germany; and "Department of Pathology and Laboratory Medicine, The University of North Carolina, Chapel Hill, North Carolina 27599
}

\begin{abstract}
The $\mathrm{G}_{\mathrm{M} 2}$ gangliosidoses are a group of severe, neurodegenerative conditions that include Tay-Sachs disease, Sandhoff disease, and the $G_{\mathrm{M} 2}$ activator deficiency. Bone marrow transplantation (BMT) was examined as a potential treatment for these disorders using a Sandhoff disease mouse model. BMT extended the life span of these mice from $\sim 4.5$ mo to up to $8 \mathrm{mo}$ and slowed their neurologic deterioration. BMT also corrected biochemical deficiencies in somatic tissues as indicated by decreased excretion of urinary oligosaccharides, and lower glycolipid storage and increased levels of $\beta$-hexosaminidase activity in visceral organs. Even with neurologic improvement, neither clear reduction of brain glycolipid storage nor improvement in neuronal pathology could be detected, suggesting a complex pathogenic mechanism. Histological analysis revealed $\beta$-hexosaminidase-positive cells in the central nervous system and visceral organs with a concomitant reduction of colloidal iron-positive macrophages. These results may be important for the design of treatment approaches for the $\mathrm{G}_{\mathrm{M} 2}$ gangliosidoses. (J. Clin. Invest. 1998. 101:1881-1888.) Key words: beta- $N$-acetylhexosaminidase/metabolism - gangliosidoses/physiopathology • blood-brain barrier - Tay-Sachs disease/metabolism • disease models, animal
\end{abstract}

\section{Introduction}

The $\mathrm{G}_{\mathrm{M} 2}$ gangliosidoses are lysosomal storage disorders caused by impaired degradation of $\mathrm{G}_{\mathrm{M} 2}$ ganglioside (GalNAc $\beta 1 \rightarrow 4$ $(\mathrm{NeuAc} \alpha 2 \rightarrow 3) \mathrm{Gal} \beta 1 \rightarrow 4 \mathrm{Glc} \beta 1 \rightarrow 1 \mathrm{Cer})$ and related substrates (reviewed in references 1 and 2). This group of disorders includes Tay-Sachs disease, Sandhoff disease, and the $\mathrm{G}_{\mathrm{M} 2}$ activator deficiency. In each, $\mathrm{G}_{\mathrm{M} 2}$ ganglioside and related lipids massively accumulate in neuronal lysosomes, triggering a pathologic process that ultimately results in severe central ner-

Address correspondence to Dr. Richard L. Proia, Building 10, Room 9D-20, 10 Center Dr., MSC 1810, National Institutes of Health, Bethesda, MD 20892. Phone: 301-496-6774; FAX: 301-496-9878; E-mail: proia@nih.gov

Received for publication 25 October 1997 and accepted in revised form 13 February 1998.

J. Clin. Invest.

(C) The American Society for Clinical Investigation, Inc. 0021-9738/98/05/1881/08 \$2.00

Volume 101, Number 9, May 1998, 1881-1888

http://www.jci.org vous system $(\mathrm{CNS})^{1}$ dysfunction. The clinical phenotypes of the diseases are nearly identical. In the most severe forms, the disease begins during the first year of life. Rapidly progressing neurodegeneration results in death usually by $4 \mathrm{yr}$ of age. There is no effective treatment.

Through targeted disruption of the Hexb gene (the mouse gene encoding the $\beta$-hexosaminidase $\beta$ subunit), we have established a mouse model for Sandhoff disease that closely recapitulates the human disorder (3). These animals lack $\beta$-hexosaminidase $\mathrm{A}$ and $\mathrm{B}$ activities and, as a consequence, accumulate large amounts of $\mathrm{G}_{\mathrm{M} 2}$ ganglioside and $\mathrm{G}_{\mathrm{A} 2}$ glycolipid (GalNAc $\beta 1 \rightarrow 4 \mathrm{Gal} \beta 1 \rightarrow 4 \mathrm{Glc} \beta 1 \rightarrow 1 \mathrm{Cer}$ ) throughout the CNS. They display a variety of neurologic manifestations including spasticity, muscle weakness, tremor, and ataxia. Death occurs between 4 and 4-1/2 mo of age.

Bone marrow transplantation (BMT) has emerged as a potential treatment for some types of lysosomal storage disorders (4-10). It is believed that donor cells, primarily of the monocyte-macrophage-microglia lineage, repopulate target organs and provide a source of the missing lysosomal enzyme. In both lysosomal disease patients and corresponding animal models, BMT can produce dramatic improvements in many of the somatic manifestations. However, improvement of CNS function by BMT in lysosomal storage disorders has been more difficult to assess. Dramatically different results have been obtained depending on the disease or model.

The Sandhoff disease mouse model affords an opportunity to investigate the effect of BMT on a prototypical gangliosidosis with severe CNS dysfunction. In this study, we show that BMT of Sandhoff disease mice with wild-type marrow resulted in increased life span and improved neurologic function. Interestingly, the clinical benefit occurred without an apparent biochemical reduction in total brain $G_{M 2}$ and $G_{A 2}$ glycolipid storage or noticeable morphological changes in neurons, suggesting a complex pathogenic disease process. The results may be important in the design of therapeutic regimes for the treatment of Sandhoff disease and related disorders.

\section{Methods}

Experimental animals. The procedures were approved by the National Institute of Diabetes and Digestive and Kidney Diseases and National Institute of Mental Health Animal Care and Use Commit-

1. Abbreviations used in this paper: BMT, bone marrow transplantation; CNS, central nervous system; FACE, fluorophore-assisted carbohydrate electrophoresis; PAS, periodic acid-Schiff; X-Hex, 5-bromo-4-chloro-3-indolyl $N$-acetyl- $\beta$-D-glucosaminide . 
tees and followed the National Institutes of Health guidelines, "Using Animals in Intramural Research." A male chimeric mouse derived from $\mathrm{J} 1$ embryonic stem cells carrying a disrupted Hexb gene (3) was crossed with a $129 / \mathrm{SvEv}$ female to produce Hexb $+/$ - mice on the 129 background. Hexb-/- mice were subsequently produced through the breeding of the Hexb+l- mice. The Hexb genotype of the mice was determined by enzyme analysis of mouse tail extracts and by Southern blot analysis. Wild-type $129 / \mathrm{SvEv}$ mice were obtained from Taconic Farms Inc. (Germantown, NY).

Bone marrow transplantation. A BMT protocol similar to that used for the Twitcher mouse was employed (4). Donor bone marrow was obtained by flushing the femurs of wild-type $129 / \mathrm{SvEv}$ mice with Hank's balanced salt solution. Recipient mice were between 10 and $16 \mathrm{~d}$ of age. After receiving 9 Gys of radiation from a ${ }^{137} \mathrm{Cs}$ source $1 \mathrm{~d}$ before transplantation, they were injected with $0.2 \mathrm{ml}$ containing 5-7 $\times$ $10^{7}$ cells i.p. The recipient mice were returned to their mothers and housed in autoclaved cages with sterile food and water to minimize the risk of infection.

Urinary oligosaccharides. Urinary oligosaccharide analysis was performed using fluorophore-assisted carbohydrate electrophoresis (FACE) (11). First, the creatinine content was determined for each urine sample using a kit obtained from Sigma Chemical CO. (No. 555-A; St. Louis, MO). Then, aliquots of urine normalized to creatinine concentration were incubated overnight at $37^{\circ} \mathrm{C}$ with the ANTS (8-aminonaphthalene 1,3,6-trisulfonic acid, disodium salt) reagent followed by high-resolution PAGE and visualization using the FACE imaging system (Glyko, Inc., Novato, CA).

$\beta$-Hexosaminidase enzyme analysis. Animals were killed when they were unable to stand or feed. The tissues, including spleen, liver, kidney, brain, and spinal cord, were immediately removed and stored at $-80^{\circ} \mathrm{C}$. A portion of each tissue $(0.1-1.0 \mathrm{~g})$ was homogenized with PBS containing $0.1 \%$ Triton X-100 to prepare a $10 \%$ extract. An aliquot of the extract was assayed for $\beta$-hexosaminidase activity with 4-methylumbelliferyl-2-acetamido-2-deoxy- $\beta$-D-glucopyranoside (12). Samples were normalized by the total protein present in the extract using a protein assay system (Bio-Rad Laboratories, Richmond, CA).

Glycolipid analysis. Sphingolipids were isolated from tissues and $\mathrm{G}_{\mathrm{M} 2}$ ganglioside and $\mathrm{G}_{\mathrm{A} 2}$ glycolipid were quantitated as described (3).

Behavioral testing. Three tests were used to ascertain neurologic function: rotorod, open field, and righting reflex. The ability to maintain balance on a rotating cylinder was measured with a standard rotorod apparatus (Economy Rotamex; Columbus Instruments, Columbus, $\mathrm{OH}$ ). The cylinder was $4.0 \mathrm{~cm}$ in diameter and was covered with textured rubber. Mice were confined to a section of the cylinder $8.75 \mathrm{~cm}$ long by black plexiglas dividers. Each mouse was placed on the cylinder, which was rotating at $10.0 \mathrm{rpm}$. Latency to fall off the rotating cylinder was measured. Mice that fell in $<15 \mathrm{~s}$ were given a second trial. Mice that did not fall during the 60 -s trial period were removed and given a score of $60 \mathrm{~s}$. Rotorod testing was conducted once per week for $5 \mathrm{wk}$. Exploratory locomotor activity was measured in an open field measuring $45 \times 45 \mathrm{~cm}$, over a 5 -min period. A Digiscan apparatus (RXYZCM; Omnitech Electronics, Columbus, $\mathrm{OH}$ ) automatically recorded and analyzed the behavioral parameters. The apparatus contained eight photocells in each horizontal direction and eight photocells elevated $4.0 \mathrm{~cm}$ to measure vertical rearings. Horizontal activity comprised the total number of photocell beam breaks in the horizontal plane during the 5-min testing session. Locomotor activity was measured once per week for $5 \mathrm{wk}$.

The righting reflex was measured by turning the mouse on its back on a flat stainless steel surface. Latency to turn itself upright was recorded. Mice not righting themselves within $10 \mathrm{~s}$ were turned rightside up and assigned a score of 10 . Mice were tested at 18 and $24 \mathrm{wk}$ of age.

Pathology. A total of six Hexb-/- mice transplanted with wildtype bone marrow (two each at $50 \mathrm{~d}, 4 \mathrm{mo}$, and $7 \mathrm{mo}$ old) were used for morphologic analysis. These were compared with two 50-d-old Hexb-1- mice that received Hexb-/- bone marrow cells and with two 50-d-old wild-type mice that received wild-type bone marrow cells and four untreated Hexb-1- mice, 4 mo of age. Two 6-mo-old $H e x b-/-$ mice that received wild-type bone marrow cells, their wild-type littermates, and a 4-mo-old untreated Hexb-/- mouse were used for histochemical demonstration of $\beta$-hexosaminidase with 5-bromo-4-chloro-3-indolyl $N$-acetyl- $\beta$-D-glucosaminide (X-Hex). Also used for X-Hex histochemistry were selected sections of the brain and spinal cord of untreated Hexb-/ - mice and Hexb-/ - mice that received wild-type bone marrow cells ( $50 \mathrm{~d}$ and 4 mo old).

All mice were anesthetized and perfused with $4 \%$ paraformaldehyde. The brains of the 50-d-old mice were cut sagittally at the midline. The right half of the brain and portions of the liver, spleen, kidney, heart, lung, and rib cartilage were processed for paraffin embedding. One coronal section of the left cerebral hemisphere at the level of the optic chiasm and one sagittal section of the cerebellar vermis, cervical spinal cord, and cervical dorsal root ganglion, left trigeminal nerve and ganglion, portions of the liver, spleen, and kidney were processed for plastic resin embedding for semi-thin light microscopic and electron microscopic studies. The remainders of the left cerebral and cerebellar hemispheres were processed as serial frozen sections. Frozen sections were also prepared from the cervical spinal cord, left trigeminal nerve and ganglion, portions of liver, spleen, kidney, and rib. The brains of the two 4-mo-old Hexb-/- and the two 7-mo-old BMT-treated Hexb-/- mice were sectioned sagittally and the right half of cerebrum, cerebellum, brainstem, spinal cord at cervical, thoracic, and lumbar levels, eye, optic, trigeminal, and sciatic nerves, bone, skin, liver, spleen, rectum, and kidney were processed for plastic resin embedding for semi-thin section light and electron microscope studies. The same tissues from the right half of the brain and eye, spinal cord, and visceral organs were processed for light microscopic studies. The entire cerebrum, cerebellum, and brainstem of two Hexb-/- mice and two Hexb-/- transplanted with wild-type bone marrow were processed by frozen, semi-serial sectioning. Frozen sections were also prepared from the cervical spinal cord, liver, kidney, and spleen. Paraffin sections were stained with Solochrome and eosin, colloidal iron, Luxol-fast blue and periodic acid-Schiff (PAS) for the nervous system and hematoxylin and eosin, colloidal iron, and PAS for the visceral organs. The brain and tissues from visceral organs for frozen sections were immersed in fixative overnight. After cryoprotection by immersion in $0.1 \mathrm{M}$ phosphate buffer $(\mathrm{pH}$ 7.4) containing $20 \%$ sucrose, the tissues were snap frozen and sections were stained either by PAS or processed for X-Hex histochemistry for detection of $\beta$-hexosaminidase. The procedures for enzyme detection were essentially the same as described (13).

Statistical analysis. Two-group comparisons were made using unpaired $t$ tests. Three-group comparisons were made using analysis of variance. Analyses of performance over time were made using repeated-measures ANOVA (RMANOVA). Post-hoc comparisons were made using Bonferroni-corrected $t$ tests. ANOVAs (F-ratio, $F$ ) and $t$ tests $(t)$ are used to calculate the ratio of between-groups variance to within-group variance. Larger $F$ and $t$ values indicate greater variability between groups than within groups and thus larger differences between group means. Degrees of freedom (df) for the F-ratio numerator equals the number of groups minus one and, for the denominator, the number of subjects minus the number of groups. Degrees of freedom on RMANOVAs were corrected for sphericity using the Greenhouse-Geyser epsilon: $\mathrm{df}($ corrected $)=\mathrm{df} *$ epsilon.

\section{Results}

Life span. Sandhoff disease (Hexb-/-) mice, 10-16 d old, were transplanted with bone marrow cells from wild-type 129/ SvEv mice. Untreated Hexb-/- animals became moribund from 101 to $139 \mathrm{~d}$ after birth, following a rapidly progressive neurodegenerative course (Fig. 1) (3). Hexb-/- mice treated by BMT lived significantly longer (203-254 d after birth) than the untreated mice $(P<0.0001)$. None of the wild-type mice 


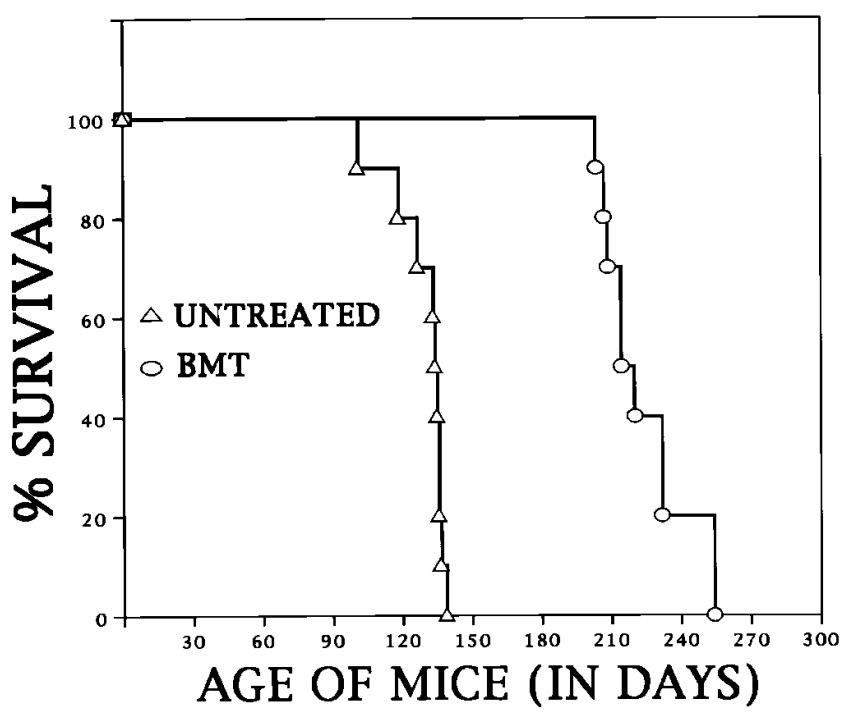

Figure 1. Survival of Hexb-/- mice after BMT. Hexb-/- mice $(n=10), 10-16 \mathrm{~d}$ of age, were transplanted with bone marrow cells from wild-type $129 / \mathrm{SvEv}$ mice. These and untreated Hexb-/- mice $(n=10)$ were monitored daily. They were killed when they were unable to feed or stand.

died during this period. The therapy resulted in a strikingly improved clinical appearance of the mice at a time when the untreated mice were severely affected with disease manifestations. In Fig. 2, a comparison of littermates at $135 \mathrm{~d}$ of age illustrates the extremely grave condition of untreated mice. At this terminal stage in the disease, they exhibit muscle wasting, rigidity, and a nearly complete inability to ambulate. In contrast, the littermates receiving BMT were active and mobile and had a normal appearance with the exception of a lighter coat color due to the radiation received as part of the transplant procedure.
Neurologic function. Rotorod performance, a measure of balance and mobility, was determined in the transplanted mice from 13 to $17 \mathrm{wk}$ of age (Fig. $3 a$ ). The performance of the wild-type, untreated $H e x b-/-$ and the $H e x b-/-$ mice given BMT differed between the three groups $\left(F_{2,30}=111.62, P<\right.$ 0.0001). Post-hoc analysis showed that the rotorod performance of the transplanted mice was significantly better than that of the untransplanted Hexb-/- mice $\left(t_{19}=3.48, P=\right.$ $0.0025)$. The performance of the untreated Hexb-/- mice and the transplanted mice deteriorated significantly over the course of the testing period $\left(F_{2,10}=16.68, P=0.0008\right.$ for the untreated Hexb-I- and $F_{1,22}=5.61, P=0.012$ for the BMTtreated mice). The ability of the wild-type mice to stay on the rotorod did not change significantly $\left(F_{2,32}=0.52, P=0.668\right)$ over the testing period, and they performed significantly better than both the Hexb-/- $\left(t_{18}=14.98, P<0.0001\right)$ and the BMT-treated mice $\left(t_{23}=10.44, P<0.0001\right)$. To determine whether the radiation received as part of the transplant procedure might have had a detrimental effect on performance, irradiated wild-type mice were transplanted with wild-type bone marrow cells. These mice performed normally on the rotorod, indicating that the radiation does not impair performance (data not shown).

The mice were tested to measure horizontal locomotor activity in a Digiscan automated open field (Fig. $3 b$ ). There were significant differences in horizontal activity among the wildtype, untreated Hexb-/-, and the transplanted Hexb-/mice $\left(F_{2,30}=9.40, P=0.0007\right)$, and a significant overall decrease in the activity of the mice over the 5-wk testing period $\left(F_{2,86}=44.04, P<0.0001\right)$, which usually represents habituation to the novelty of the open field. Post-hoc analysis showed that the wild-type mice were significantly more active in the horizontal plane than both the untreated Hexb $-1-\left(t_{18}=4.43\right.$, $P=0.0003)$ and the transplanted mice $\left(t_{23}=2.68, P=0.013\right)$. There was no significant difference in aggregate horizontal activity between the transplanted and untreated Hexb-/- mice $\left(t_{19}=1.74, P=0.097\right)$ over the 5 -wk testing period. However, at $16\left(t_{19}=2.65, P=0.0157\right)$ and $17\left(t_{19}=3.38, P=0.0032\right) \mathrm{wk}$

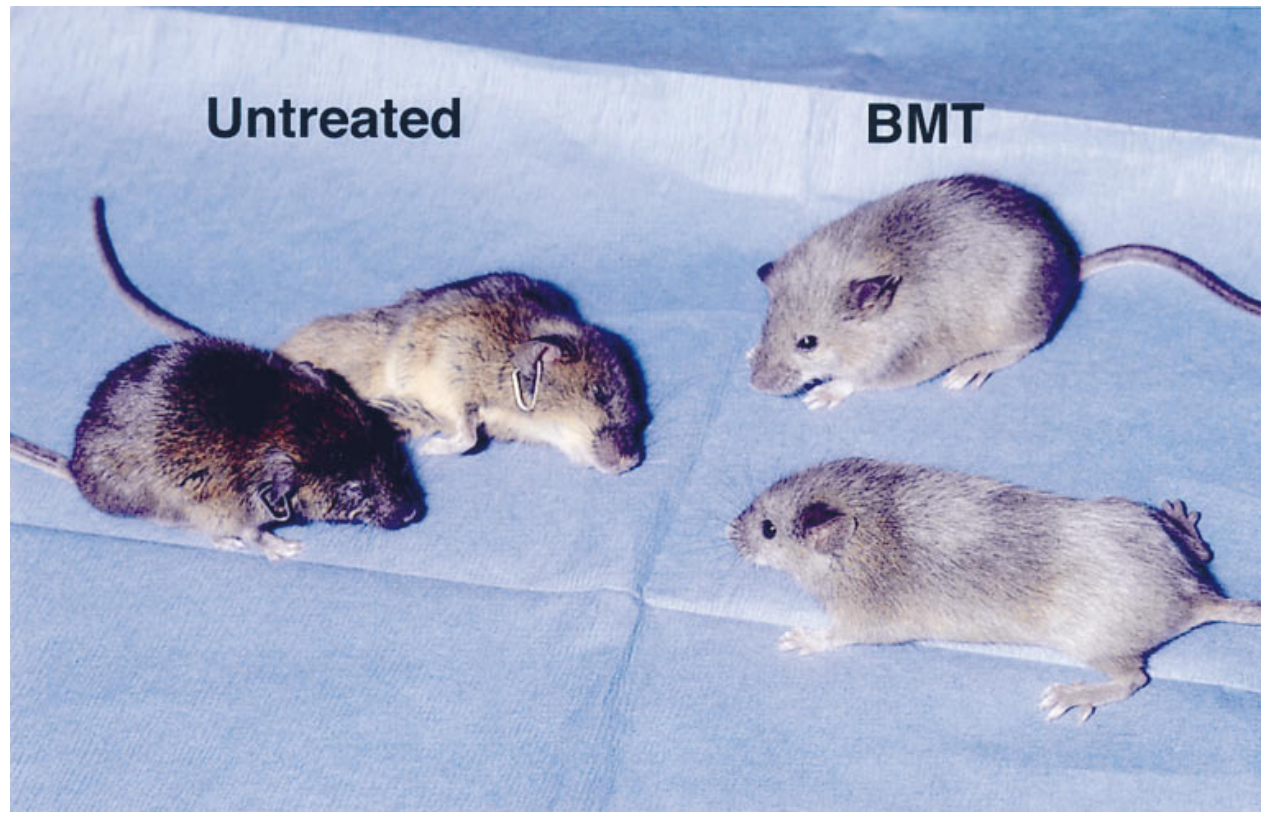

Figure 2. Clinical appearance of untreated Hexb-/ - mice and Hexb-1- after BMT. Hexb-1littermates, two untreated and two treated by BMT, were photographed at $135 \mathrm{~d}$ of age. 

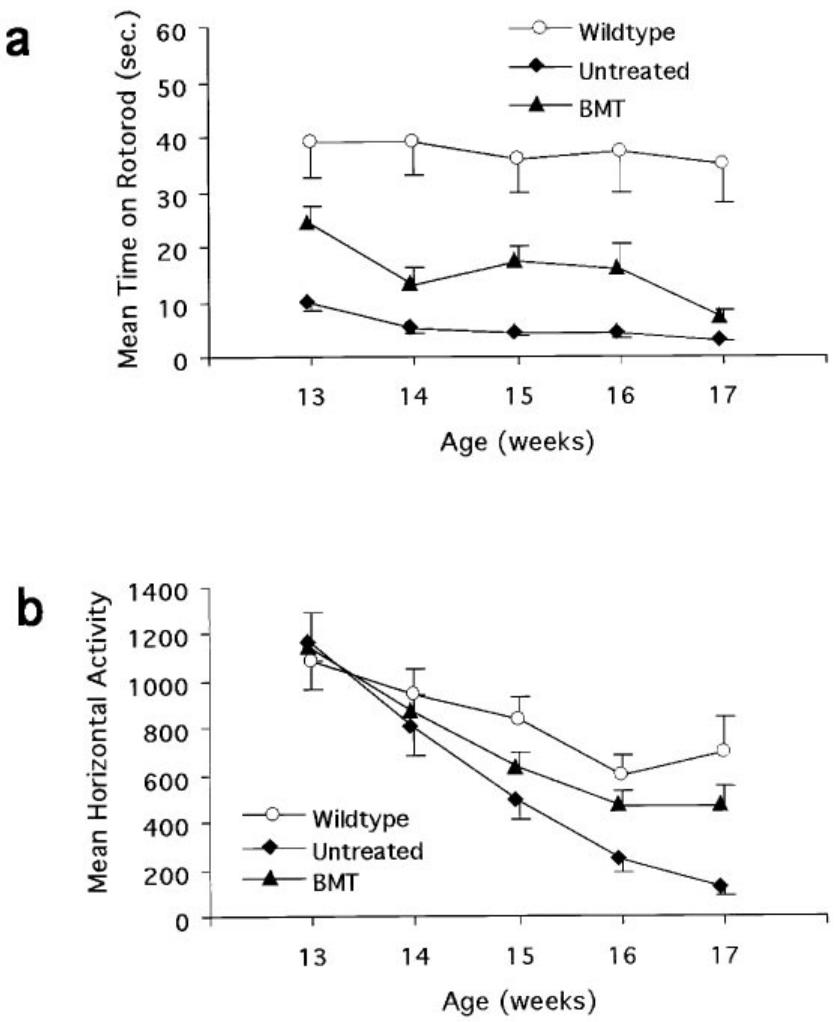

C

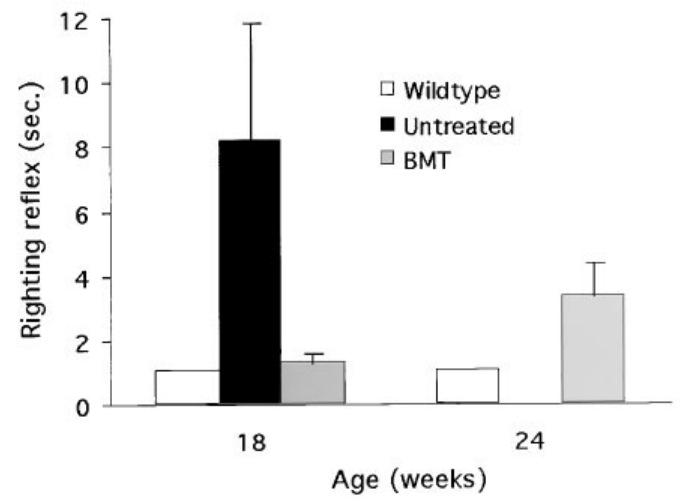

Figure 3. Behavioral testing of the Hexb-/- mice after BMT. (a) Mean $( \pm$ SEM) time to fall off the rotorod. Wild-type $(n=12)$, Hexb-I- $(n=8)$, and Hexb-I- mice transplanted with wild-type bone marrow cells $(n=13)$ were tested. $(b)$ Mean $( \pm$ SEM) horizontal activity (measured by the number of photocell beam breaks). The same groups of mice were tested in $a$ and $b$. (c) The righting reflex was tested at $18 \mathrm{wk}$ of age for wild-type $(n=12), \operatorname{Hexb}-/-(n=5)$, and Hexb-/- mice transplanted with wild-type bone marrow cells $(n=11)$ and at $24 \mathrm{wk}$ of age for wild-type $(n=12)$, and Hexb-/mice transplanted with wild-type bone marrow cells $(n=7)$. The untreated Hexb-/- mice did not live to 24 wk of age.

of age, the transplanted mice were significantly more active in the horizontal plane than the untreated Hexb-/- mice. In the radiation control experiment, horizontal activity of the irradiated wild-type mice transplanted with wild-type bone marrow was normal, indicating that the transplant procedure itself did not impair horizontal activity (data not shown).
The righting reflex was measured by turning the mice on their backs and determining the latency for turning themselves upright (Fig. $3 c$ ). There were significant differences in the righting reflex across groups measured at $18 \mathrm{wk}$ of age $\left(F_{2,25}=\right.$ 35.23, $P<0.0001)$. Post-hoc analysis showed that the untreated Hexb-/ - mice had a significantly impaired righting reflex compared with both the wild-type $\left(t_{15}=6.51, P<0.0001\right)$ and the Hexb-1- mice receiving BMT $\left(t_{14}=5.63, P<\right.$ 0.0001). The Hexb-/- mice given BMT were not significantly different from wild-type mice $\left(t_{21}=1.01, P=0.307\right)$. The wildtype and seven of the Hexb-/- mice receiving BMT were retested at $24 \mathrm{wk}$ of age. Although the BMT-treated mice appeared to be more impaired, the difference between the two groups $\left(t_{17}=4.20, P=0.0561\right)$ was not statistically significant. The untreated Hexb-/- mice did not survive to $24 \mathrm{wk}$ of age.

Biochemistry. Sandhoff disease patients excrete oligosaccharides in the urine as a result of an impaired ability to degrade oligosaccharides terminating in $\mathrm{N}$-acetylglucosamine (1, 2). Through FACE analysis (11) of urinary oligosaccharides, we observed that high molecular weight oligosaccharides were abnormally increased in urine of the untreated Hexb-/- mice (Fig. 4). The level of these oligosaccharides was reduced to near normal by BMT treatment.

The BMT-treated mice had dramatically higher levels of $\beta$-hexosaminidase in the spleen and liver compared with untreated mice (Fig. 5). Small but statistically significant increases in the level of enzyme in the kidney, brain, and spinal cord were also observed.

Levels of $\mathrm{G}_{\mathrm{M} 2}$ ganglioside and $\mathrm{G}_{\mathrm{A} 2}$ glycolipid were examined in livers and brains of Hexb-/ - mice treated by BMT (Fig. 6). A substantial reduction in the storage of these glycolipids was found in the liver of mice treated by BMT when compared with untreated Hexb-I- mice. However, in these

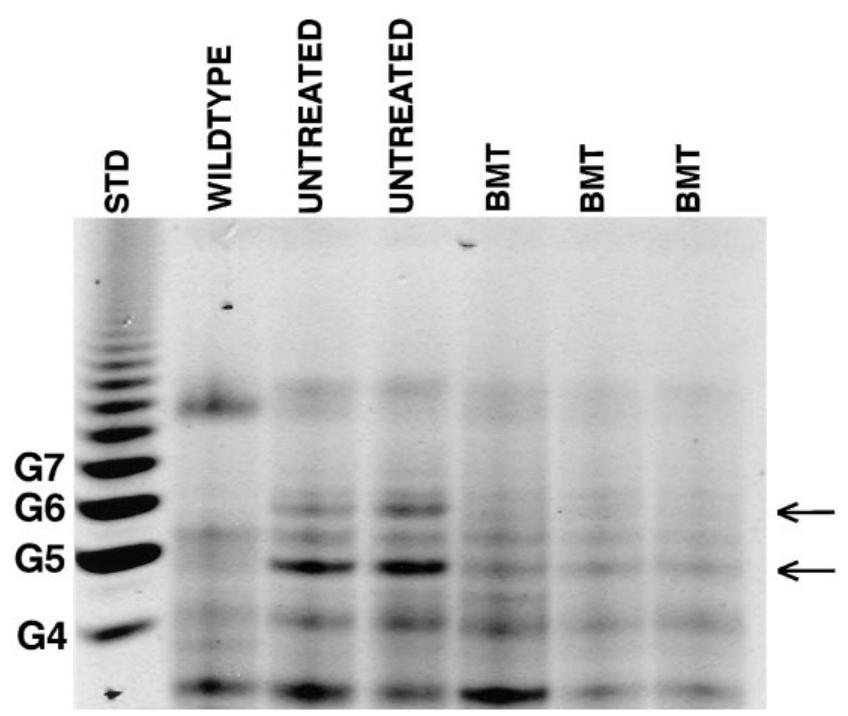

Figure 4. Excretion of urinary oligosaccharides after BMT. Urine was collected from wild-type, untreated Hexb-/-, and Hexb-/mice $48 \mathrm{~d}$ after BMT. FACE was performed to analyze urinary oligosaccharides. The arrows shown indicate the high molecular weight oligosaccharides present in the Hexb-/ - control urine but greatly reduced in the BMT-treated mice. High molecular weight oligosaccharides are those larger than the tetrasaccharide standard (G4). The size standards consist of glucose polymers. 


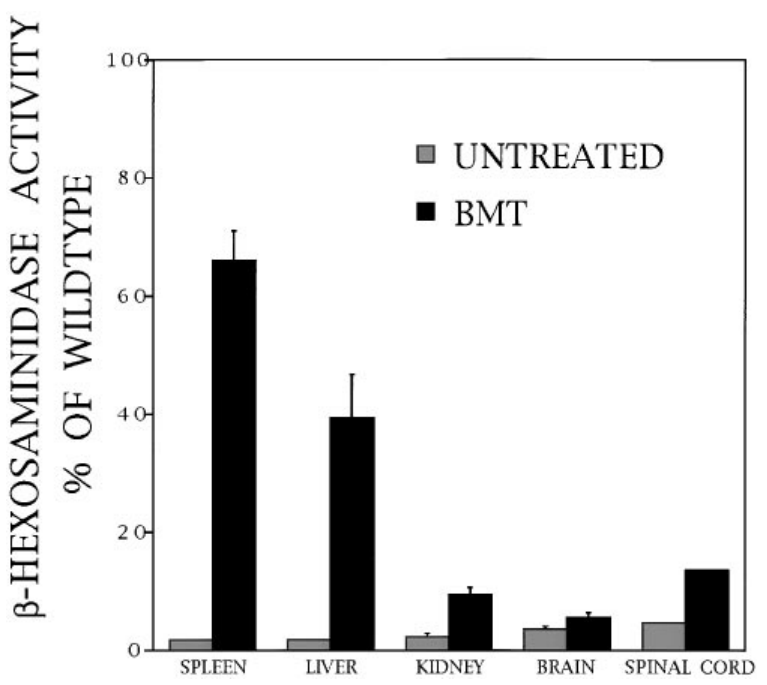

Figure 5. $\beta$-Hexosaminidase activity in tissues of Hexb-/- mice after BMT. Spleen, liver, kidney, and brain were analyzed from BMTtreated Hexb-I- mice $(n=12)$, untreated Hexb-l- mice $(n=12)$ and wild-type mice $(n=11)$. The analysis of spinal cord enzyme was performed on two BMT-treated Hexb-/- mice and three untreated $H e x b-1-$ mice. The results are expressed as percentage of wild-type levels $( \pm$ SEM $)$. The differences between spleen $\left(t_{21}=13.58, P<\right.$ $0.0001)$, liver $\left(t_{21}=5.01, P<0.0001\right)$, kidney $\left(t_{21}=5.42, P<0.0001\right)$, brain $\left(t_{21}=2.54, P=0.019\right)$, and spinal cord $\left(t_{3}=39.03, P<0.0001\right)$ from BMT-treated and untreated mice are statistically significant.

same mice, levels of $\mathrm{G}_{\mathrm{M} 2}$ and $\mathrm{G}_{\mathrm{A} 2}$ storage in the brain were not substantially different.

Pathology. To determine if there was pathologic improvement mediated by BMT, Hexb-/- mice, transplanted with either wild-type or Hexb-/- bone marrow cells, were evaluated without prior knowledge of treatment. In both types of mice, storage was diffusely and variably present in the cerebrum, cerebellum, brainstem, and spinal cord. From semi-serial frozen sections, comparisons were made in specific regions: cerebral cortex, hippocampus, septal nuclei, amygdala, striatum, hypothalamus, cerebellum, facial nuclei, and hypoglossal nuclei. There was no discernible difference in the degree of storage in the brain in these regions irrespective of the source of bone marrow. The only histologic difference identified between the brains of the mice was the presence of colloidal ironstained macrophages. Colloidal iron staining generally indicates the storage of glycosaminoglycans, and positive cells have been noted previously in this model (14). In untreated Hexb-/- mice and in Hexb-/- mice transplanted with Hexb-/- marrow, colloidal iron-positive cells were identified in the leptomeninges, in perivasacular locations, and within the brain parenchyma. These colloidal iron-positive cells were nearly absent in Hexb-/- mice transplanted with wild-type marrow (Fig. 7, $a$ and $b$ ). In a sagittal section (5- $\mu \mathrm{m}$ thick) of the entire brain of an untreated Hexb-/- mouse and a Hexb-/- mouse transplanted with Hexb-/- marrow, 15-20 colloidal iron-positive cells were identified. While comparable sections of two Hexb-/- mice transplanted with wild-type marrow showed either two or no colloidal iron-positive cells. 7-mo-old Hexb-/- mice transplanted with wild-type marrow showed extensive neuronal storage that appeared even greater than in untreated 4-mo-old Hexb-/- mice. However, there were many fewer colloidal iron-positive macrophages in the brain of the 7-mo-old transplanted mouse compared with the untreated 4-mo-old mouse.

Colloidal iron-stained macrophages were found in the liver and kidney of untreated Hexb-/- mice and in Hexb-/- mice transplanted with Hexb-/- bone marrow cells. None of these storage cells could be detected in animals transplanted with wild-type bone marrow cells. In Hexb-/- mice, untreated or transplanted with Hexb-/- bone marrow cells, renal tubular epithelial cells showed a vacuolated appearance and stained positively with colloidal iron. This abnormal pathology in kidney was absent in all ages of Hexb-/- mice transplanted with wild-type marrow.

Histochemical staining with X-Hex enabled the detection of $\beta$-hexosaminidase-containing cells. Strong X-Hex staining was detected within neurons and glial cells in wild-type mice. The stain was particularly strong in cells located in perivascular regions in the brain and in the leptomeninges. No X-Hexpositive reaction was noted in any tissues of Hexb-/- mice nor in Hexb-/- mice transplanted with Hexb-/- bone marrow cells. In Hexb-/- mice transplanted with wild-type bone marrow cells, many positive cells were identified in the spleen with fewer in liver and kidney. Positive cells were also noted in the brain and spinal cord of Hexb-/- mice transplanted with wild-type bone marrow cells (Fig. $7, c-e$ ). In some cases, the positive cells appeared to be in association with blood vessels (Fig. $7 d$ ). With the increasing age of the Hexb-/- mice transplanted with wild-type bone marrow cells, the numbers of $\mathrm{X}$-Hex positive cells in brain appeared to increase.

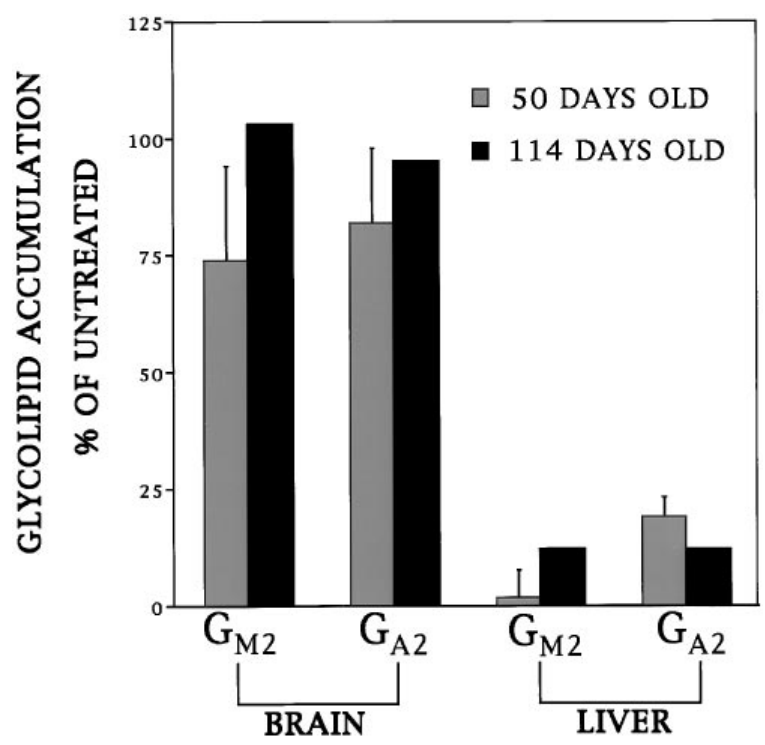

Figure 6. Glycolipid accumulation in the brain and liver of Hexb-/mice treated with BMT. The sphingolipid fraction of brain and liver was isolated and separated by thin layer chromatography. The amounts of $\mathrm{G}_{\mathrm{M} 2}$ ganglioside and $\mathrm{G}_{\mathrm{A} 2}$ glycolipid were quantitated by scanning the plates. The results are expressed as glycolipid storage relative to Hexb-/- control mice of the same age ( \pm SEM). The background level of $\mathrm{G}_{\mathrm{M} 2}$ ganglioside in wild-type liver was subtracted from the liver values. Analysis was performed on three 50-d-old and one 114-d-old Hexb-/- mice treated by BMT. 


\section{Colloidal Iron}
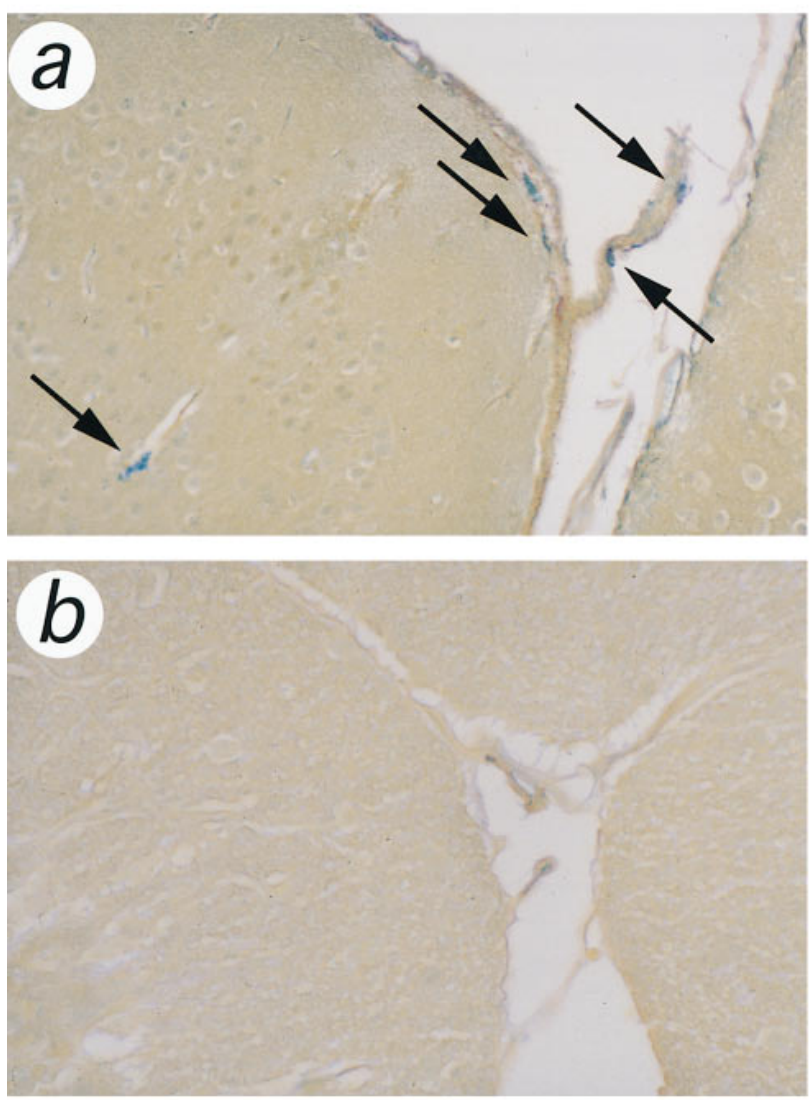

Figure 7. Elimination of colloidal iron-positive cells and introduction of $\beta$-hexosaminidase-positive cells in the CNS after BMT. (a) Colloidal iron staining of the cerebral cortex of a 4-mo-old Hexb-/- mouse treated by BMT with Hexb-/- marrow cells $(100 \times)$. Arrows indicate positive cells, presumably macrophages, in the leptomeninges and perivascular region. Similar results were seen with untreated Hexb-/- mice. (b) Colloidal iron staining of the cerebral cortex of a 4-mo-old Hexb-/- mouse treated by BMT with wild-type marrow cells $(100 \times)$. No colloidal iron-positive cells were present. Histochemical detection of $\beta$-hexosaminidase-positive cells in the CNS of a 6-mo-old Hexb-/- mouse that received BMT $(c-e)$. (c) Cerebral white matter $(200 \times)$. (d) Cerebral cortex $(100 \times)$. Note that the positive cells appear closely aligned with a blood vessel. (e) Spinal cord $(20 \times)$. Arrows indicate cells showing the blue $\mathrm{X}-\mathrm{Hex}$ reaction product.

\section{Discussion}

BMT has been used, with varying degrees of success, to treat disorders caused by lysosomal enzyme deficiencies in humans and in laboratory animals. There are several examples showing that BMT can be effective at supplying enzyme to visceral organs and in eliminating somatic disease manifestations $(5,6,9$, 15-17). In contrast, the effectiveness of BMT for the correction of CNS manifestations in lysosomal disorders has been much more difficult to evaluate. This is particularly true in human disorders where, in addition to the inherent difficulties of human experimentation, there may be wide variability in clinical manifestations of a given disease.

\section{X-Hex}
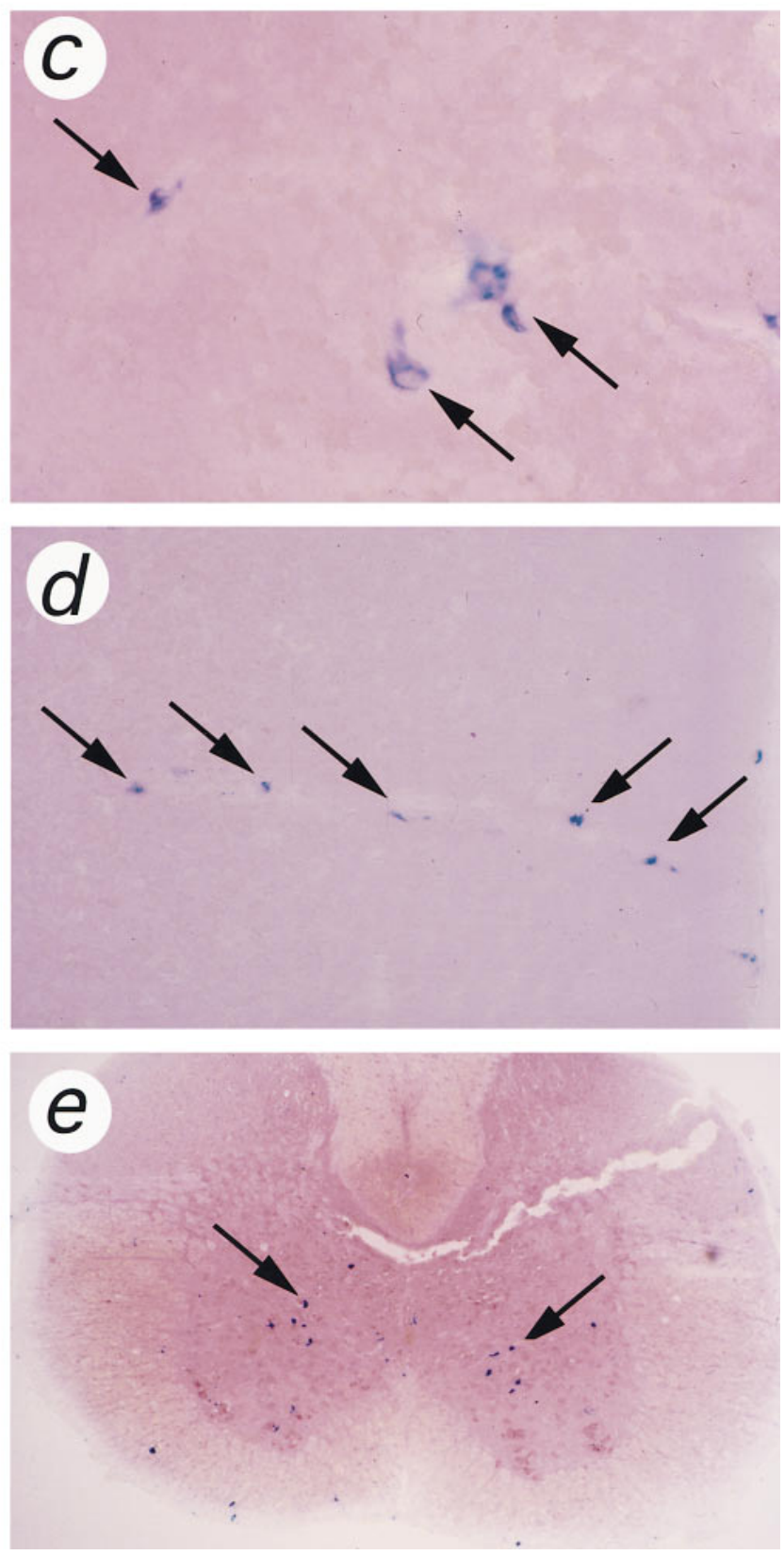

Perhaps the most striking example of successful BMT treatment of CNS disease was in the $\alpha$-mannosidosis cat model (13). BMT was highly effective in preserving the neurologic function and lengthening the life span. Neurons of the treated animals exhibited histochemical evidence of $\alpha$-mannosidase activity and a reduction in storage. A second clear example of CNS improvement after BMT was in the Twitcher mouse, an animal model of globoid cell leukodystrophy (Krabbe disease) $(4,18,19)$. BMT resulted in increased life span and increased galactosylceramidase levels in the central nervous system. Krabbe disease is an exceptional "storage" disease because the major natural substrate of the missing enzyme does not accumulate. Instead, increased levels of a cytotoxic metabolite, 
galatoctosylsphingosine (psychosine), mediates the disease pathology. Its levels are decreased after BMT. In both the $\alpha$-mannosidosis and the Krabbe disease models, it appeared the therapeutic effect of BMT was mediated by donor derived macrophages/microglia crossing the blood-brain barrier to supply the missing enzyme. Improvement in the neurologic function of canine models of MPS I and fucosidosis has also been reported $(15,20)$. Prolonged survival with somatic improvement was shown with the murine model of MPS VII after BMT (5). Although a decrease in neuronal storage was noted after treatment (16), improvement in neurologic function could not be documented (21).

Sandhoff disease mice exhibit the prototypical features of a sphingolipidosis: massive neuronal storage of glycolipid and a fulminant neurodegenerative course. Ultimately, the pathogenic process leads to apoptosis of neurons (22). BMT treatment was shown to ameliorate the disease process by extending the life span of the mice by up to 4 mo and delaying the onset of severe neurologic manifestations. Enhanced performance on behavioral tests assessing motor function was additional evidence that CNS function was preserved by BMT. Eventually, the BMT-treated mice underwent a disease process similar to the untreated Sandhoff disease mice, indicating that only a partial correction was effected.

A small increase of $\beta$-hexosaminidase activity and enzymepositive cells was detected in the brain and spinal cord of BMT-treated animals. By analogy with previous BMT experiments in the $\alpha$-mannosidosis cat and Krabbe disease mouse, these enzyme-positive cells likely represent brain macrophages or microglia of donor origin that provided a means of enzyme introduction into the CNS $(13,19)$. The reduction of colloidal iron-positive cells in the brain after BMT treatment is consistent with a systemic repopulation by normal, donor-derived macrophages/microglia. The therapeutic mechanism mediated by these donor cells is not readily apparent since we could not find clear evidence of a decrease in glycolipid storage in the brain either through biochemical or pathologic analysis. These results suggest that the pathogenesis of the disease is not totally dominated by bulk $\mathrm{G}_{\mathrm{M} 2}$ and $\mathrm{G}_{\mathrm{A} 2}$ glycolipid storage in the brain.

The neurologic improvement could be due to a very localized correction of neuronal storage that is not detectable by quantitation of bulk glycolipid. However, a number of specific CNS locations were compared on PAS-stained, frozen sections in BMT-treated and control mice, but regional differences in storage were not readily evident. The apparent lack of appreciable differences in pathology between BMT-treated and control mice could also be due to difficulty in discriminating subtle quantitative differences morphologically. Alternatively, the BMT may selectively reduce the levels of a minor toxic metabolite such as lyso- $\mathrm{G}_{\mathrm{M} 2}$ that may mediate neuropathogenesis in this disorder. Lyso- $\mathrm{G}_{\mathrm{M} 2}$ has been detected in the brains of TaySachs and Sandhoff patients but at levels much below the main storage products $(1,23)$. The occurrence of such a compound may elicit a cytotoxic pathogenic mechanism analogous to psychosine in Krabbe disease. It is also conceivable that these slightly water-soluble lysogangliosides were released from brain and visceral organs and were eliminated by the large amount of $\beta$-hexosaminidase activity present in somatic tissues and blood due to BMT.

An interesting possibility for the disease amelioration by BMT may be related to the observation that colloidal iron- positive macrophages, present in untreated mice, were virtually absent in the brains of Sandhoff mice treated by BMT. Other studies have shown that microglia/macrophages can be activated by neurodegeneration to secrete toxic factors such as cytokines and initiate an inflammatory cascade (24-26). In the Sandhoff mice, initial neuronal degeneration and storage by macrophages may trigger an activation of macrophages that, in turn, promote tissue damage through an inflammatory process. Replacement of the enzyme-deficient macrophage population with normal macrophages by BMT may temporarily delay or remove this pathogenic component of the disease process.

In contrast to the apparent inability of BMT treatment to reduce glycolipid storage in the brain, glycolipid storage in liver and spleen (not shown) was greatly reduced. BMT was also effective in lowering the excretion of oligosaccharides in urine and in reducing kidney pathology. The correction of these somatic manifestations after BMT is readily explained by the large amounts of $\beta$-hexosaminidase activity in visceral organs and the systemic normalization of the macrophage population as suggested by the disappearance of colloidal iron-positive cells.

The ultimate demise of the BMT-treated Sandhoff disease mice and the very small amount of enzyme introduced into the CNS indicates that this treatment alone may not be highly effective for infantile forms of the $\mathrm{G}_{\mathrm{M} 2}$ gangliosidoses where virtually no degradative capacity exists. Increased efficacy might be possible by genetically engineering donor cells to hypersecrete enzyme or by combining BMT with glycolipid synthesis inhibitors (27) in an attempt to more closely balance the synthesis and degradation of substrate. In the late-onset forms of the disorder, however, where residual enzyme is already present, a small increase in CNS enzyme activity (if possible by BMT) might greatly improve the clinical course of the disease (28).

\section{Acknowledgments}

We thank Paul Plotz for comments on the manuscript. This work is submitted by F. Norflus in partial fulfillment of the Ph.D. requirements in the Graduate Genetics Program at the George Washington University.

This work was supported in part by United States Public Health Service grants RO1-NS 24453 and P30-HD 03110 to Ki. Suzuki and the Deutsche Forschungsgemeinschaft (SFB 284) to Ko. Sandhoff.

\section{References}

1. Sandhoff, K., E. Conzelmann, E.F. Neufeld, M.M. Kaback, and K. Suzuki. 1989. The $\mathrm{G}_{\mathrm{M} 2}$ gangliosidoses. In The Metabolic Basis of Inherited Disease. C.R. Scriver, A.L. Beaudet, W.S. Sly, and D. Valle, editors. McGraw-Hill Inc., New York. 1807-1839.

2. Gravel, R.A., J.T.R. Clarke, M.M. Kaback, D. Mahuran, K. Sandhoff, and K. Suzuki. 1995. The $\mathrm{G}_{\mathrm{M} 2}$ gangliosidoses. In The Metabolic and Molecular Basis of Inherited Disease. C.R. Scriver, A.L. Beaudet, W.S. Sly, and D. Valle, editors. McGraw-Hill Inc., New York. 2839-2879.

3. Sango, K., S. Yamanaka, A. Hoffmann, Y. Okuda, A. Grinberg, H. Westphal, M.P. McDonald, J.N. Crawley, K. Sandhoff, K. Suzuki, and R.L. Proia. 1995. Mouse models of Tay-Sachs and Sandhoff diseases differ in neurologic phenotype and ganglioside metabolism. Nat. Genet. 11:170-176.

4. Suzuki, K., P.M. Hoogerbrugge, B.J.H.M. Poorthuis, D.W. Van Bekkum, and K. Suzuki. 1988. The twitcher mouse: central nervous system pathology after bone marrow transplantation. Lab. Invest. 58:302-309.

5. Birkenmeier, E.H., J.E. Barker, C.A. Vogler, J.W. Kyle, W.S. Sly, B. Gwynn, B. Levy, and C. Pegors. 1991. Increased life span and correction of metabolic defects in murine mucopolysaccharidosis type VII after syngeneic bone marrow transplantation. Blood. 78:3081-3092. 
6. Hoogerbrugge, P.M., O.F. Brouwer, P. Bordigoni, O. Ringden, P. Kapaun, J.J. Ortega, A. O’Meara, G. Cornu, G. Souillet, D. Frappaz, et al. 1995. Allogenic bone marrow transplantation for lysosomal storage diseases. Lancet. 345:1398-1402.

7. Walkley, S.U., and K. Dobrenis. 1995. Bone marrow transplantation for lysosomal diseases. Lancet. 345:1382-1383.

8. Krivit, W., J.H. Sung, E.G. Shapiro, and L.A. Lockman. 1995. Microglia: the effector cell for reconstitution of the central nervous system following bone marrow transplantation for lysosomal and peroxisomal storage diseases. Cell Transplant. 4:385-392.

9. Zhou, X.Y., H. Morreau, R. Rottier, D. Davis, E. Bonten, N. Gillemans, D. Wenger, F.G. Grosveld, P. Doherty, K. Suzuki, et al. 1995. Mouse model for the lysosomal disorder galactosialidosis and correction of the phenotype with overexpressing erthroid precursor cells. Genes Dev. 9:2623-2634.

10. Haskins, M. 1996. Bone marrow transplantation therapy for metabolic diseases: animal models as predictors of success and in utero approaches. Bone Marrow Transplant. 18:S25-S27.

11. Starr, C.M., R.I. Masada, C. Hague, E. Skop, and J.C. Klock. 1996. Fluorophore-assisted carbohydrate electrophoresis in the separation, analysis, and sequencing of carbohydrates. J. Chromatogr. A. 720:295-321.

12. Kaback, M.M. 1972. Thermal fractionation of serum hexosaminidases: applications to heterozygote detection and diagnosis of Tay-Sach's disease. Methods Enzymol. 28:862-867.

13. Walkley, S.U., M.A. Thrall, K. Dobrenis, M. Huang, P.A. March, D.A. Siegel, and S. Wurzelmann. 1994. Bone marrow transplantation corrects the enzyme defect in neurons of the central nervous system in a lysosomal storage disease. Proc. Natl. Acad. Sci. USA. 91:2970-2974.

14. Sango, K., M.P. McDonald, J.N. Crawley, M.L. Mack, C.J. Tifft, E. Skop, C.M. Starr, A. Hoffmann, K. Sandhoff, K. Suzuki, and R.L. Proia. 1996. Mice lacking both subunits of lysosomal $\beta$-hexosaminidase exhibit mucopolysaccharidosis and gangliosidosis. Nat. Genet. 14:348-352.

15. Shull, R.M., N.E. Hastings, R.R. Selcer, J.B. Jones, J.R. Smith, W.C. Cullen, and G. Constantopoulos. 1987. Bone marrow transplantation in canine mucopolysaccharidosis. I : Effects within the central nervous system. J. Clin. Invest. 79:435-443.

16. Sands, M.S., J.E. Barker, C. Vogler, B. Levy, B. Gwynn, N. Galvin, W. Sly, and E. Birkenmeier. 1993. Treatment of murine mucopolysaccharidosis type VII by syngeneic bone marrow transplantation in neonates. Lab. Invest. 68:676-686.

17. Sands, M.S., C. Vogler, A. Torrey, B. Levy, B. Gwynn, J. Grubb, W.S. Sly, and E.H. Birkenmeier. 1997. Murine mucopolysaccharidosis type VII: long term therapeutic effects of enzyme relacement and enzyme replacement followed by bone marrow transplantation. J. Clin. Invest. 99:1596-1605.

18. Hoogerbrugge, P.M., B.J. Poorthuis, G. Wagemaker, D.W. van Bekkum, and K. Suzuki. 1989. Alleviation of neurologic symptoms after bone marrow transplantation in Twitcher mice. Transplant. Proc. 21:2980-2981.

19. Hoogerbrugge, P.M., K. Suzuki, K. Suzuki, B.J. Poorthuis, T. Kobayashi, G. Wagemaker, and D.W. van Bekkum. 1988. Donor-derived cells in the central nervous system of twitcher mice after bone marrow transplantation. Science. 239:1035-1038.

20. Taylor, R.M., B.R.H. Farrow, G.J. Stewart, P.J. Healy, and K. Tiver. 1987. Lysosomal enzyme replacement in neural tissue by allogenic bone marrow transplantation following total lymphoid irradiation in canine fucosidosis. Transplant. Proc. 19:2730-2734.

21. Bastedo, L., M.S. Sands, D.T. Lambert, M.A. Pisa, E. Birkenmeier, and P.L. Chang. 1994. Behavioral consequences of bone marrow transplantation in the treatment of murine mucopolysaccharidosis type VII. J. Clin. Invest. 94: 1180-1186.

22. Huang, J.Q., J.M. Trasler, S. Igdoura, J. Michaud, N. Hanal, and R.A. Gravel. 1997. Apoptotic cell death in mouse models of GM2 gangliosidosis and observations on human Tay-Sachs and Sandhoff diseases. Hum. Mol. Genet. 6: 1879-1885.

23. Neuenhofer, S., E. Conzelmann, G. Schwarzmann, H. Egge, and K. Sandhoff. 1988. Occurrence of lysoganglioside lyso-G M2 $_{\text {(II3-Neu5Ac-ganglio- }}$ triaosylsphingosine) in $\mathrm{G}_{\mathrm{M} 2}$ gangliosidosis brain. Biol. Chem. Hoppe-Seyler. 367: 241.

24. Dickson, D.W., S.C. Lee, L.A. Mattiace, S.H. Yen, and C. Brosnan. 1993. Microglia and cytokines in neurological disease, with special reference to AIDS and Alzheimer's disease. Glia. 7:75-83.

25. Licinio, J., and M.L. Wong. 1997. Pathways and mechanisms for cytokine signaling of the central nervous system. J. Clin. Invest. 100:2941-2947.

26. Griffin, D.E. 1997. Cytokines in the brain during viral infection: clues to HIV-associated dementia. J. Clin. Invest. 100:2948-2951.

27. Platt, F.M., G.R. Neises, G. Reinkensmeier, M.J. Townsend, H.V Perry, R.L. Proia, B. Winchester, R.A. Dwek, and T.D. Butters. 1997. Prevention of lysosomal storage in Tay-Sachs mice treated with $N$-butyldeoxynojirimycin. Science. 276:428-431.

28. Leinekugel, P., S. Michel, E. Conzelmann, and K. Sandhoff. 1992 Quantitative correlation between the residual activity of $\beta$-hexosaminidase A and arylsulfatase A and the severity of the resulting lysosomal storage disease. Hum. Genet. 88:513-523. 